\title{
Morphological Studies on the Skull Bones of Indian Mithun (Bos frontalis)
}

\author{
O.P. Choudhary, Priyanka1', P.C. Kalita, S. Dalga², A. Kalita, P.J. Doley, Keneisenuo
}

10.18805/IJAR.B-4279

\begin{abstract}
Background: There is scanty information on the skull morphology of Indian mithun. Therefore, the present study has been designed to provide information on the morphology of the skull of Indian mithun.

Method: The study was conducted on the skull bones of twelve $(n=12)$ adult Indian mithun of either sex $(n=6$, male and $n=6$, female).

The head region samples of naturally died mithun were collected from different parts of the Mizoram and Nagaland states of India from April, 2019 to March, 2020.

Result: The skull of mithun was roughly triangular in shape from the dorsal side. The cranial and facial bones were the major components of the skull, with a total of thirty-two bones. There were three single and four paired cranial bones with a total of eleven bones. There was one single and the rest were paired facial bones with a total of twenty-one bones. The cranial bones were occipital, parietal, interparietal, sphenoid, ethmoid, frontal and temporal. The facial bones were maxilla, premaxilla (incisive), palatine, pterygoid, nasal, lacrimal, zygomatic (malar), vomer, turbinate, mandible and hyoid. The present morphological studies on the skull of mithun can be useful to the wildlife professionals and zoo veterinarians for the determination of sex of this animal and differentiation from other domestic and wild animals for solving veterolegal cases.
\end{abstract}

Key words: Mithun, Morphological, Skull.

\section{INTRODUCTION}

Mithun (Bos frontalis) is also known as gayal or 'Cattle of Mountain' is a rare bovine species living under free-range conditions inside the tropical rainforest ecosystems of India, Bangladesh, Bhutan, China and Myanmar (Mondol et al., 2004). It is a unique animal having a massive body, with characteristic 'white stockings' on their stout legs. This animal efficiently converts grass, forage, tree leaves as well as various agricultural by-products into highly nutritious meat (Mukherjee et al., 2019). Mithun plays a vital role in the socio-economic and cultural life of the local tribal population in the northeast region of India (Mondol et al., 2007; Shisode et al., 2009; Mondal et al., 2014). The first de novo draft genome assembly of Indian mithun has recently been studied in detail (Mukherjee et al., 2019).

The skull morphology of various domestic and wild animals have been studied in detail; however, the information on the skull morphology of Indian mithun is scanty, which prompted the conduction of present study.

\section{MATERIALS AND METHODS}

The study was conducted on the skull bones of twelve $(n=12)$ adult Indian mithun of either $\operatorname{sex}(n=6$, male and $n=6$, female). The head region samples of naturally died mithun were collected from different parts of the Mizoram and Nagaland states of India from April, 2019 to March, 2020. All the procedures involving sample collection were conducted as per the Institutional Animal Ethics Committee (IAEC), which is under the Committee for the Purpose of Control and Supervision of Experiments on Animals (CPCSEA), Ministry of Environment, Forest and
Department of Veterinary Anatomy and Histology, College of Veterinary Sciences and Animal Husbandry, Central Agricultural University (I), Selesih, Aizawl-796 015, Mizoram, India.

${ }^{1}$ Department of Veterinary Microbiology, College of Veterinary Sciences and Animal Husbandry, Central Agricultural University (I), Jalukie, Peren-797 110, Nagaland, India.

${ }^{2}$ Department of Anatomy, Faculty of Veterinary Medicine, Kafkas University, Kars, Turkey.

Corresponding Author: O.P. Choudhary, Department of Veterinary Anatomy and Histology, College of Veterinary Sciences and Animal Husbandry, Central Agricultural University (I), Selesih, Aizawl796 015, Mizoram, India. Email: dr.om.choudhary@gmail.com

How to cite this article: Choudhary, O.P., Priyanka, Kalita, P.C., Dalga, S., Kalita, A., Doley, P.J. and Keneisenuo (2022). Morphological Studies on the Skull Bones of Indian Mithun (Bos frontalis). Indian Journal of Animal Research. 56(1): 40-45. DOI: $10.18805 /$ IJAR.B-4279.

Submitted: 10-08-2020 Accepted: 18-11-2020 Online: 29-12-2020

Climate Change, Government of India for the College of Veterinary Sciences and Animal Husbandry, Selesih, Aizawl, Mizoram, Aizawl, Mizoram.

After collection, the head region samples of mithun were processed by the hot water maceration technique (Choudhary et al., 2013a, b; 2015). The skulls and mandibles were kept in $3 \%$ hydrogen peroxide for three days and further sun-dried for seven days (Choudhary et al., 2018b). The morphological studies on the skull of Indian mithun were carried out in the Department of Veterinary Anatomy and Histology, College of Veterinary Sciences and Animal Husbandry, Selesih, Aizawl, Mizoram. 


\section{RESULTS AND DISCUSSION}

In the present study, the skull of mithun was roughly triangular (Fig 1) from the dorsal side as reported earlier in chital (Ramswarup, 2011) and goat of Mizoram (Choudhary et al., 2020); however, it was pyramidal in ox (Raghavan, 1964) and elongated in kagani goat (Sarma, 2006), blackbuck (Choudhary and Singh, 2016) and chinkara (Din et al., 2020). The cranial and facial bones were the skull's major components, with a total of thirty-two bones. There were three single and four paired cranial bones with a total of eleven bones. There was one single and the rest were paired facial bones with a total of twenty-one bones. The cranial bones were occipital, parietal, interparietal, sphenoid, ethmoid, frontal and temporal. The facial bones were maxilla, premaxilla (incisive), palatine, pterygoid, nasal, lacrimal, zygomatic (malar), vomer, turbinate, mandible and hyoid as reported earlier in ox (Raghavan, 1964), dog (Miller et al., 1964), ruminants (Sisson, 1975), horse (Getty, 1975), savannah buffalo (Hornsveld, 2002), chital (Parmar and Shrivastava, 2003; Kumawat et al., 2014) and blackbuck (Choudhary and Singh, 2016).

The dorsal surface (Fig 1) of the skull of mithun was formed by the frontal, nasal and incisive bones. In contrast, it was formed by occipital, parietal, interparietal, frontal, nasal and incisive bones in kagani goat (Sarma, 2006) and chital (Ramswarup, 2011) and formed by frontal, parietal, nasal and incisive bones in chinkara (Din et al., 2020). The dorsal surface of the skull of the mithun was extensive in its caudal third. The greatest width of the dorsal surface was noticed at the level of the dorso-caudal margin of the orbital rim.

The frontal bone was irregularly quadrilateral in shape and extensive in mithun as also reported earlier in ox (Raghavan, 1964) and yak (Archana et al., 1998a). The frontal bone presented an undulated surface with a distinct interfrontal suture. The cornual processes emerged from the caudolateral angle of the frontal bone with a broad base. They were caudolaterally directed and terminated to a tapering end. The cornual processes were slender in diameter and oriented in a dorso-caudal fashion in ox (Raghavan, 1964). The intercornual protuberance was less developed and located caudally between the cornual processes in the Indian mithun. In contrast, the intercornual protuberance was more developed in ox (Getty, 1975) and absent in yak (Archana et al., 1998a). The supraorbital foramen was a small opening placed slightly caudal to the caudal margin of the orbital rim on the obliquely oriented supraorbital groove (Fig 1); however, the same foramen was situated in the supraorbital groove near to the medial margin of the orbit in ox (Raghavan, 1964); chital (Ramswarup, 2011) and blackbuck (Choudhary and Singh, 2016), whereas it was located within the orbital portion of the frontal bone in bovine (Diesem, 1968); in the supraorbital groove of the medial brim of the orbit in chinkara (Din et al., 2019); in the middle to the median margin of the orbital rim in chital (Parmar and Shrivastava, 2003). Singh and Patel (1964) also mentioned that the supraorbital foramen was closer to the orbital margin than to the median line (interfrontal suture). In another study, the supraorbital foramen was a huge opening in the blackbuck (Choudhary and Singh, 2016).

The nasal bone formed the greater part of the roof of the nasal cavity, which was also reported in ox (Raghavan, 1964) and tiger (Joshi, 2004). The nasal bone in the present study was articulated cranially with incisive bone and caudally with the frontal bone as reported earlier in blackbuck (Choudhary and Singh, 2016). The nasal bone was inserted into the frontal bone as a loose attachment as stated earlier in horse (Getty, 1975), chital (Kumawat et al., 2014) and blackbuck (Choudhary and Singh, 2016); however same attachment was closely adherent in ox (Raghavan, 1964) and sambar deer (Archana et al., 2003).

The ventral surface (Fig 2) of the skull of mithun can be divided into cranial, choanal and palatine regions. The basioccipital bone in mithun was shorter as compared to that of ox (Raghavan, 1964). The muscular tubercles were seen to be less developed and widely placed in mithun. The tympanic bulla was small, laterally compressed and less prominent in mithun as also reported in kagani goat (Sarma, 2006) and Mehraban sheep (Karimi et al., 2011). In contrast, the same was large in ox (Raghavan, 1964) and chital (Ramswarup, 2011). The articular area for the mandibular condyle was found to be wide and flattened in outline in mithun. The placement of the ovale foramen, orbitorotundum foramen and ethmoidal foramen in mithun was similar to the findings in ox (Raghavan, 1964) and blackbuck (Choudhary and Singh, 2016).

The palatine region was wide and concave in mithun as reported earlier in ox (Getty, 1975). The palatine region was formed by the palatine process of the incisive bone, the maxilla and horizontal plates of palatine bones and was circumscribed laterally by the alveolar parts of the maxilla as reported earlier in ox (Raghavan, 1964). The major palatine foramina (Fig 4) were placed close to the transverse

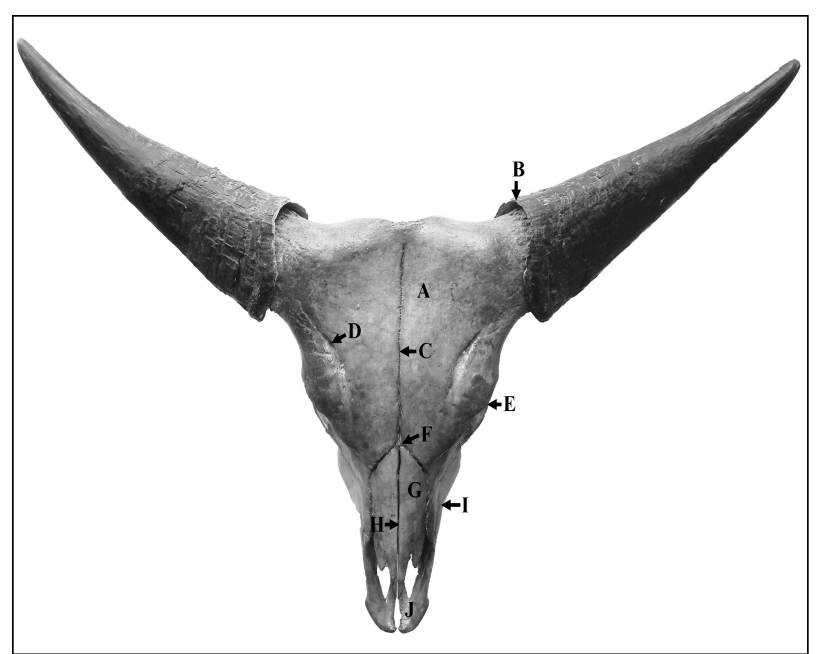

Fig 1: Dorsal view of the skull of mithun showing frontal bone $(A)$, horn (B), interfrontal suture (C), supraorbital foramen in the supraorbital groove $(D)$, orbit $(E)$, frontonasal suture $(F)$, nasal bone $(\mathrm{G})$, internasal suture $(\mathrm{H})$, maxilla bone $(\mathrm{I})$ and incisive bone $(\mathrm{J})$. 
palatine suture in mithun as reported earlier in blackbuck (Choudhary and Singh, 2016). The palatine fissure and interincisive canal were similar to that of ox (Getty, 1975). However, the body of the incisive bone (Fig 4) was found to be more flattened in mithun. The maxilla and palatine bones presented eight alveoli for cheek teeth as earlier described in ox, sheep (Getty, 1975) and yak (Archana et al., 1998a).

The nuchal surface of the skull was formed by the occipital bone as also reported earlier in camel (Shahid and Kausar, 2005), blackbuck (Choudhary and Singh, 2016) and Bardhoka autochthonous sheep breed (Gündemir et al., 2020). The placement of occipital bone in mithun resembled that of horse (Getty, 1975), camel (Singh, 1984), dog (Miller et al., 1964), chital (Ramswarup, 2011) and blackbuck (Choudhary and Singh, 2016). The nuchal surface in the skull of mithun was constricted in the middle due to the well developed temporal fossa. This surface was more extensive dorsoventrally as compared to ox (Raghvan, 1964) and formed mostly by the squamous and lateral parts of the occipital bone. The external occipital protuberance (Fig 5) was pointed and well developed; however, it was in the form of a thin prominent crest in Binturong (Kalita et al., 2020). The mastoid foramina were paired and located at the junction between the occipital and parietal bones as mentioned earlier in ox (Raghavan, 1964) and blackbuck (Choudhary and Singh, 2016). The occipital condyles were present on the lateral parts of the occipital bone on either side of the

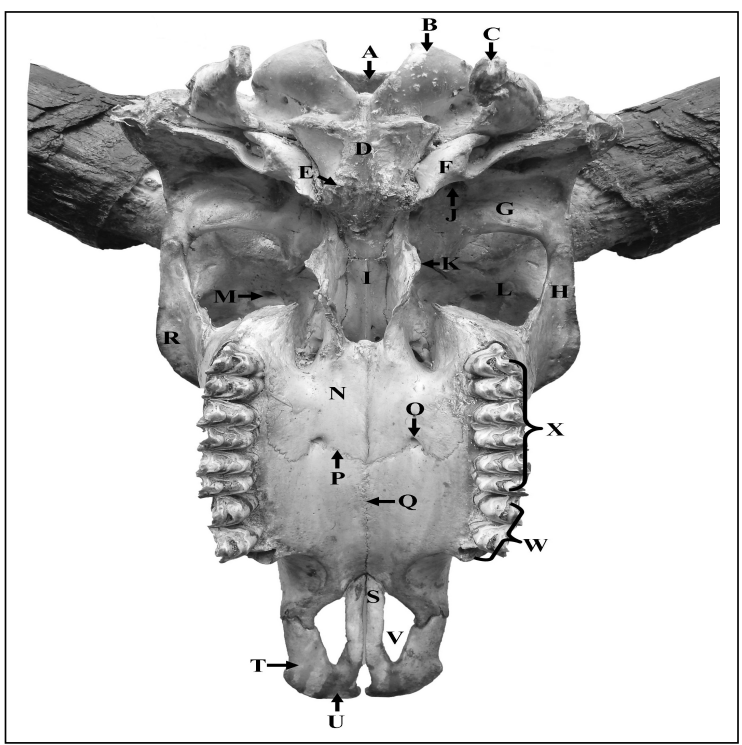

Fig 2: Ventral view of the skull of mithun showing foramen magnum $(A)$, occipital condyle $(B)$, paracondylar process $(C)$, basilar part of the occipital bone (D), muscular tubercle $(E)$, tympanic bulla $(F)$, articular tubercle $(G)$, zygomatic arch $(H)$, body of basisphenoid $(\mathrm{I})$, oval foramen $(\mathrm{J})$, pterygoid hamulus $(\mathrm{K})$, orbit $(\mathrm{L})$, supraorbital canal $(\mathrm{M})$, palatine bone $(\mathrm{N})$, greater palatine foramen $(\mathrm{O})$, zig-zag transverse palatine suture $(P)$, median palatine suture $(Q)$, zygomatic bone $(R)$, palatine process of incisive bone $(S)$, nasal process of incisive bone $(T)$, body of incisive bone $(U)$, palatine fissure $(\mathrm{V})$, premolar teeth $(\mathrm{W})$ and molar teeth $(\mathrm{X})$. foramen magnum as reported previously in blackbuck (Choudhary and Singh, 2016) and local mizo pig (Choudhary et al., 2019). The foramen magnum was large and roughly oval in shape as reported earlier in ox (Raghavan, 1964), chital (Ramswarup, 2011), blackbuck (Choudhary and Singh, 2016), chinkara (Din et al., 2019), goat of Mizoram (Choudhary et al., 2020) and Bardhoka autochthonous sheep (Gündemir et al., 2020).

The lateral surface can be divided into cranial and maxillary parts; however, they were continuous without any distinct demarcation in Indian mithun. The lateral surface of the cranial part of the skull of mithun presented a dorsoventrally flattened deep temporal fossa, which was

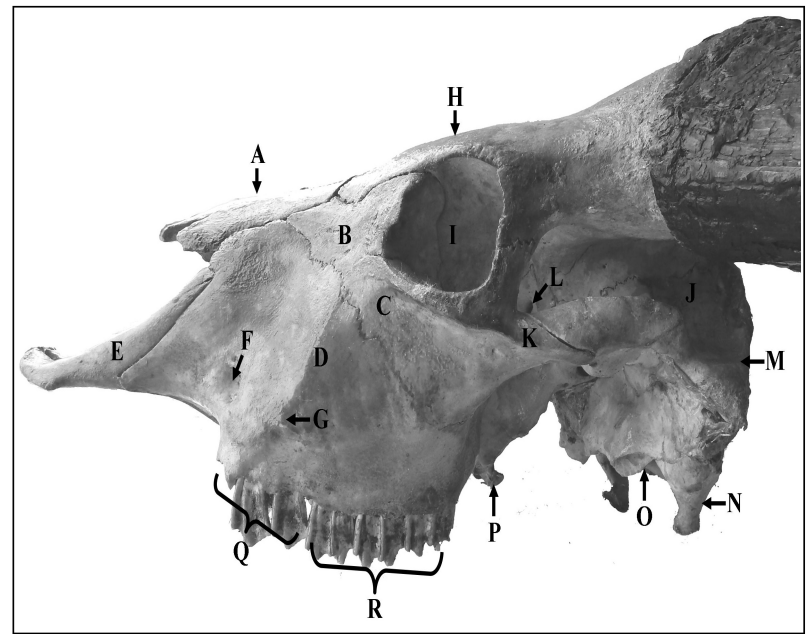

Fig 3: Lateral view of the skull of mithun showing nasal bone $(A)$, lacrimal bone (B), zygomatic bone (C), maxilla bone (D), incisive bone $(E)$, infraorbital foramen $(F)$, facial or maxillary tuberosity $(G)$, frontal bone $(H)$, orbit $(I)$, temporal fossa $(J)$, zygomatic arch $(K)$, optic foramen $(L)$, occipital bone $(M)$, paracondyloid fossa $(N)$, foramen magnum $(\mathrm{O})$, pterygoid hamulus $(\mathrm{P})$, premolar teeth $(\mathrm{Q})$ and molar teeth $(R)$.

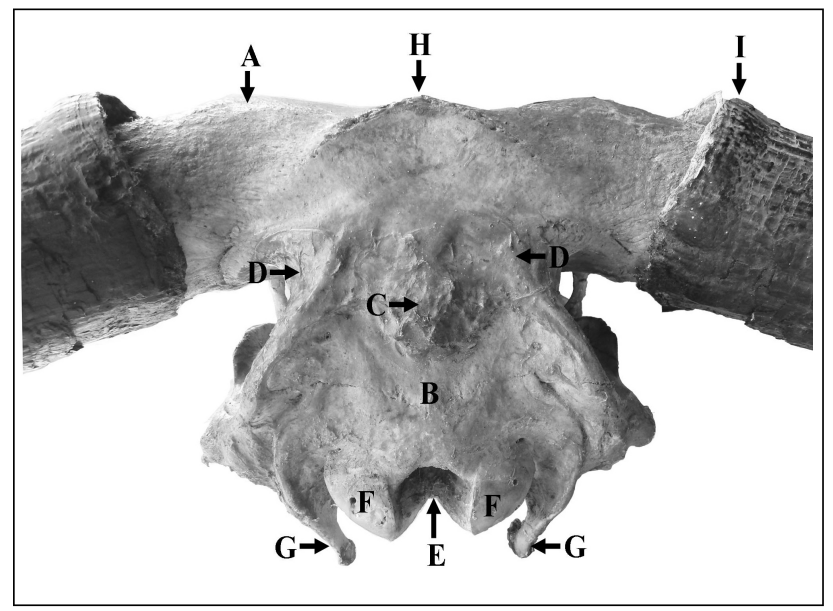

Fig 4: Nuchal view of the skull of mithun showing cornual process $(A)$, occipital bone $(B)$, external occipital protuberance $(C)$, constricted middle part $(D)$, foramen magnum $(E)$, occipital condyle $(F)$, paracondyloid process $(\mathrm{G})$, frontal bone $(\mathrm{H})$ and horn $(\mathrm{I})$. 
wider in ox (Raghavan, 1964), shallow and elongated in goat (Borthakur, 1990), deep but short in yak (Archana et al., 1998a). The zygomatic arch was massive in mithun. About four or five foramina connecting the temporal canal were present in the caudomedial surface of the temporal fossa in mithun and the same numbers of foramina were located on the ventral surface of the temporal fossa in ox (Nickel et al., 1981). The axis of the orbit taken from the optic foramen to the middle of the inlet was directed rostral, lateral and slightly dorsal in mithun like in ox as reported by Diesem (1968). The orbit was formed by the lacrimal, orbital plate of the frontal, supraorbital process, the orbital wing of the sphenoid and the zygomatic bones. The orbital rim (Fig 3) was a thin, rounded margin, smooth in mithun as in yak (Archana et al., 1998a) and goat of Mizoram (Choudhary et al., 2018a), whereas it was elliptical in bovine (Rao et al., 1968) and Mehraban sheep (Karimi et al., 2011); nearly circular in chinkara (Din et al., 2019).

The maxillary region was formed chiefly by the maxilla bone and also by the facial parts of the lacrimal and zygomatic bones. The facial tuberosity (Fig 3) was placed above the third superior premolar tooth as reported earlier in ox (Ghosh, 2012), chital (Kumawat et al., 2014), blackbuck (Choudhary and Singh, 2015) and goat of Mizoram (Choudhary et al., 2020). However, the facial tuberosity was placed at the junction of the fourth and fifth cheek teeth in Kagani goat (Sarma, 2006); prominent and placed at the level of fifth cheek tooth in Mehraban sheep (Karimi et al., 2011), Madras red sheep (Sundaram et al., 2019) and at the superior first molar tooth in Bardhoka autochthonous sheep breed (Gündemir et al., 2020). The infraorbital foramen was located at the level of the superior first premolar tooth, similar to the findings in chital (Parmar and Shrivastava, 2003); however, it was situated above the third cheek tooth in dogs (Nickel et al., 1973), above the level of second check tooth in camel (Smuts and Bezuidenhout, 1987). As reported in chinkara (Din et al., 2019), the infraorbital foramen was located at the level of the second cheek tooth; however, in goat of Mizoram (Choudhary et al., 2020), it was situated dorsally to the junction of the first and second superior premolar teeth.

The mandible (Fig 5) was the heaviest bone of the skull and both the mandibles remained unossified as also reported in spotted deer (Kumawat et al., 2014) and blackbuck (Choudhary et al., 2015); however, the mandibular symphysis was ossified in the camel (Choudhary et al., 2016), horse (Getty, 1975) and pig (Choudhary et al., 2019). The body of the mandible consisted of the rostral part and caudal part. The rostral part of the mandible contained the incisor teeth, while the caudal part consisted of the cheek teeth (Fig 5). In the present study, the cheek teeth were three on either mandible i.e., inferior incisor I, II, III as also reported previously in sambar and barking deer (Keneisenuo et al., 2020). The cheek teeth were six on either mandible i.e., three premolar teeth and three molar teeth as also reported in chital (Ramswarup, 2011), blackbuck (Choudhary et al., 2015), sambar and barking deer (Keneisenuo et al., 2020). The canine tooth was absent in the present study. The mandibular tuberosity was very prominent as reported earlier in spotted deer (Kumawat et al., 2014); however, the mandibular tuberosity was in the form of a tubercle in camel (Singh, 1984), but it was well developed in yak (Archana et al., 1998b) and it was not observed in blackbuck (Choudhary et al., 2015). The body of the mandible (Fig 6) contained the mandibular canal as earlier reported in ox (Raghavan, 1964), yak (Archana et al., 1998b), rhinoceros (Bordoloi et al., 1995), chital (Ramswarup, 2011) and blackbuck (Choudhary et al., 2015) for the passage of the mandibular artery, vein and mandibular alveolar nerve. The mandibular canal had its caudal opening mandibular foramen on the medial surface of the mandible and rostrally,

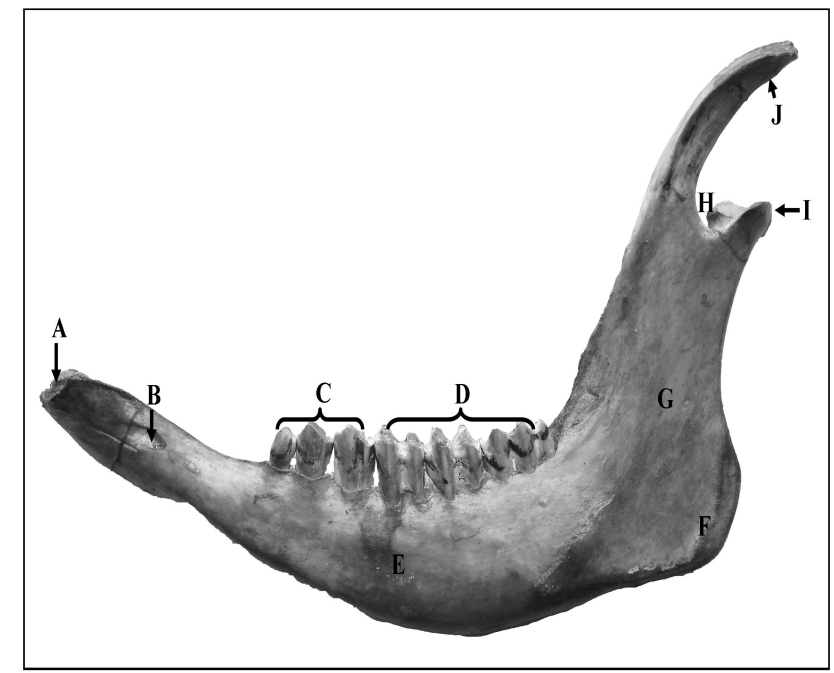

Fig 5: Lateral view of the mandible of the mithun showing socket for incisor teeth (A), mental foramen (B), premolar teeth (C), molar teeth $(D)$, body of the mandible $(E)$, mandibular angle $(F)$, ramus of mandible $(\mathrm{G})$, mandibular notch $(\mathrm{H})$, condyloid process $(\mathrm{I})$ and coronoid process $(\mathrm{J})$.

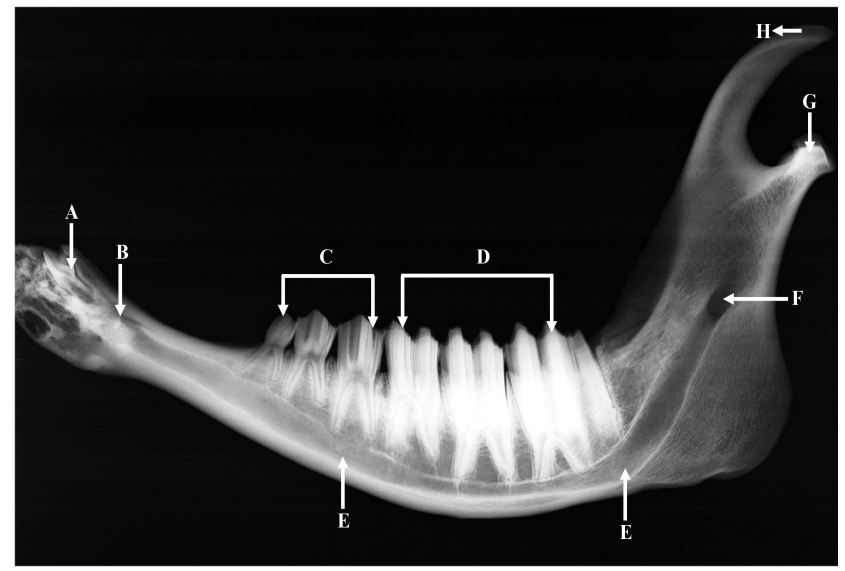

Fig 6: Mediolateral radiographical view of the mandible of the mithun showing socket for incisor teeth (A), mental foramen (B), premolar teeth $(C)$, molar teeth $(D)$, mandibular canal $(E)$, mandibular foramen $(F)$, condyloid process $(G)$ and coronoid process $(H)$. 
the mandibular canal ended with an opening as mental foramen ventral to the diastema.

\section{CONCLUSION}

It can be concluded from the present study that the skull of the mithun quite resembled to that of the small and large ruminants i.e., ox, goat, deer etc. with a few minor deviations; however, some major anatomical differences were observed when compared to the camel, horse, dog and other wild animals.

\section{ACKNOWLEDGEMENT}

The authors are thankful to the Vice-Chancellor and Director of Research, Central Agricultural University, Imphal for sanctioning the Intramural Research Project (IRP). The authors are also grateful to the Dean, College of Veterinary Sciences and Animal Husbandry, Central Agricultural University (I), Aizawl, Mizoram for providing all the necessary facilities to carry out the present research investigation.

\section{REFERENCES}

Archana., Sharma, D.N. and Kishtwaria, R.S. (2003). Anatomy of Skull of Sambar Deer. (Census unicolor). XVIII IAVA Convention Souvenir and Abstracts, 26-28 ${ }^{\text {th }}$ December 2003. Gujarat Agricsultural University, Anand Campus, Anand, Gujarat, India.

Archana., Sudhakar, L.S. and Sharma, D.N. (1998a). Anatomy of skull of yak (Bos grunniens). Indian J. Vet. Anat. 10(1/2): 9-15.

Archana., Sudhakar, L.S. and Sharma, D.N. (1998b). Anatomy of the mandible of yak (Bos grunniens). Indian J. Vet. Anat. 10(1/2): 16-20.

Bordoloi, C.C., Borthakur, S., Talukdar, S.R., Kalita, S.N., Baishya, G. and Kalita, H. (1995). Mandible of the great Indian one horned Rhinoceros (Rhinoceros unicornis). Indian Vet. J. 72(8): 838-842.

Borthakur, S. (1990). Post-natal study of the skull of Assam goats (Capra hircus) with an emphasis on sexual dimorphism. Ph.D. thesis submitted to Assam Agricultural University, Khanapara, Guwahati, Assam, India.

Choudhary, O.P. and Singh, I. (2015). Morphometrical studies on the skull of Indian blackbuck (Antilope cervicapra). Int. J. Morphol. 33(3): 868-876.

Choudhary, O.P. and Singh, I. (2016). Morphological and radiographic studies on the skull of Indian blackbuck (Antilope cervicapra). Int. J. Morphol. 34(2): 788-796.

Choudhary, O.P., Kalita, P.C., Doley, P.J., Kalita, A. and Arya, R.S. (2018a). Morphometrical studies on the orbit of goat (Capra hircus) of Mizoram. Rumin. Sci. 7(1): 71-72.

Choudhary, O.P., Kalita, P.C., Kalita, A. and Doley, P.J. (2016). Applied anatomy of the maxillofacial and mandibular regions of the dromedary camel (Camelus dromedarius). J. Camel Pract. Res. 23(1): 127-131.

Choudhary, O.P., Kalita, P.C., Konwar, B., Doley, P.J., Kalita, G. and Kalita, A. (2019). Morphological and applied anatomical studies on the head region of local Mizo pig (Zovawk) of Mizoram. Int. J. Morphol. 37(1): 196-204.
Choudhary, O.P., Kalita, P.C., Rajkhowa, T.K., Arya R.S., Kalita, A. and Doley, P.J. (2018b). Gross morphological studies on the sternum of crested serpent eagle (Spilornis cheela). Indian J. Anim. Res. 53(11): 1459-1461.

Choudhary, O.P., Mathur, R., Joshi, S., Beniwal, G. and Dangi, A. (2013a). Gross and biometrical studies on carpals of chital (Axis axis). Vet. Pract. 14(1): 36-39.

Choudhary, O.P., Mathur, R., Joshi, S., Beniwal, G. and Dangi, A. (2013b). Gross and biometrical studies on scapula of chital (Axis axis). Vet. Pract. 14(2): 224-227.

Choudhary, O.P., Priyanka, Kalita, P.C., Arya, R.S., Kalita, A., Doley, P.J. and Keneisenuo (2020). A morphometrical study on the skull of goat (Capra hircus) in Mizoram. Int. J. Morphol. 38(5): 1473-1478.

Choudhary, O.P., Singh, I., Bharti, S.K., Khan, I.M., Sathapathy, S. and Mrigesh, M. (2015). Gross and morphometrical studies on mandible of blackbuck (Antelope cervicapra). Int. J. Morphol. 33(2): 428-32.

Diesem, C. (1968). Gross anatomical structure of equine and bovine orbit and its contents. Am. J. Vet. Res. 29: 1769-1781.

Din, S., Masood, S., Zaneb, H., Rehman, H., Ashraf, S., Khan, I., Shah, M. and Hadi, S.A. (2020). Gross and clinical anatomy of the skull of adult chinkara (Gazella bennettii). Pak. J. Zool. https://dx.doi.org/10.17582/journal.pjz/201 90207070209.

Getty, R. (1975). Sisson and Grossman's: The Anatomy of the Domestic Animals, $2^{\text {nd }}$ edn., Vol. I, W.B. Saunders Co. Philadelphia, USA.

Ghosh, R.K. (2012). Primary Veterinary Anatomy. $5^{\text {th }}$ edn. Current Books International, Kolkata, West Bengal, India.

Gündemir, O., Duro, S., Jashari, T., Kahvecioğlu, O., Demircioğlu, I and Mehmeti, H. (2020). A study on morphology and morphometric parameters on skull of the Bardhoka autochthonous sheep breed in Kosovo. Anat. Histol. Embryol. doi: 10.1111/ahe.12538.

Hornsveld, M. (2002). The Osteology of the Cranial and Facial Bones of the Savannah Buffalo Syncerus caffer caffer (Sparrman, 1779). Ph.D. thesis submitted to the University of Pretoria, South Africa.

Joshi, H. (2004). Gross anatomical studies of the skull of Indian tiger (Panthera tigris). M.V.Sc. thesis submitted to the Rajasthan Agricultural University, Bikaner, Rajasthan, India.

Kalita, P.C., Debroy, S., Choudhary, O.P., Kalita, A. and Doley, P.J. (2020). Morphological and morphometrical studies on the skull of binturong (Arctictis binturong). J. Anim. Res. 10 (2): 309-314.

Karimi, I., Onar, V., Pazvant, G., Hadipour, M. and Mazaher, Y. (2011). The cranial morphometric and morphologic characteristics of Mehraban sheep in western Iran. Global Vet. 6(2): 111-117.

Keneisenuo, Choudhary, O.P., Priyanka, Kalita, P.C., Kalita, A., Doley, P.J. and Chaudhary, J.K. (2020). Applied anatomy and clinical significance of the maxillofacial and mandibular regions of the barking deer (Muntiacus muntjak) and sambar deer (Rusa unicolor). Folia Morphol. doi: 10.5603/FM. a2020.0061.

Kumawat, R., Mathur, R., Joshi, S. and Choudhary, O.P. (2014). Gross studies on cranial bones of chital (Axis axis). Ind. J. Vet. Anat. 26(1): 54-55. 
Miller, M.S., Christensen, G.C. and Evans, H.E. (1964). The Skeletal System, Skull. In Anatomy of Dog. W.B. Saunders Co., Philadelphia, USA.

Mondal, M., Baruah, K.K. and Rajkhowa, C. (2014). Mithun: An animal of Indian pride. Livest. Res. Rural Dev. 26(1): mond26006.

Mondal, M., Dhali, A., Rajkhowa, C. and Prakash, B.S. (2004). Secretion patterns of growth hormone in growing captive mithuns (Bos frontalis). Zool. Sci. 21(11): 1125-1129.

Mondol, M., Rajkhowa, C. and Prakash, B.S. (2007). Plasma growth hormone concentration in female mithun (Bos frontalis) of different ages, relation with age and body weight. $\mathrm{J}$. Anim. Physiol. Anim. Nutr. 91(1-2): 68-73.

Mukherjee, S., Cai, Z., Mukherjee, A., Longkumer, I., Mech, M., Vupru, K., Khate, K., Rajkhowa, C., Mitra, A., Guldbrandtsen, B., Lund M.S. and Sahana, G. (2019). Whole genome sequence and de novo assembly revealed genomic architecture of Indian mithun (Bos frontalis). BMC Genom. 20: 617.

Nickel, R., Schummer, A. and Seiferli, E. (1981). Anatomy of the Domestic Animals. Verlog Paul Parey, Berlin, Germany.

Nickel, R.A., Schummer, A. and Seiferle, E. (1973). Respiratory System in the Viscera of the Domestic Mammals. Translation and revision by Sack W.C., Vehag Paul Parey, Berlin, Germany.

Parmar, M.L. and Shrivastva, A.B. (2003). Anatomy of the Skull of Chital (Axis axis). XVIII IAVA Convention Souverm and Abstracts, 26-28 $8^{\text {th }}$ December 2003. Gujarat Agricultural University, Anand Campus, Anand, Gujarat, India.

Raghavan, D. (1964). Anatomy of Ox. Indian Council of Agricultural Research, New Delhi, India.
Ramswarup. (2011). Gross anatomical studies on the bones of the skull in chital (Axis axis). M.V.Sc. thesis submitted to the Rajasthan University of Veterinary and Animal Sciences, Bikaner, Rajasthan, India.

Rao, G.S., Sharma, D.N. and Saigal, R.P. (1968). The area and capacity of the bovine orbit. Indian J. Ani. Health. 7: 23-28.

Sarma, K. (2006). Morphological and craniometrical studies on the skull of Kagani goat (Capra hircus) of Jammu region. Int. J. Morphol. 24(3): 449-455.

Shahid, R.U. and Kausar, R. (2005). Comparative gross anatomical studies of the skull of one-humped camel (Camelus dromedarius). Pak. Vet. J. 25(4): 205206.

Shisode, M.G., Khanvilkar, A.V., Kulkarni, M.D., Samant, S.R., Yadav, G.B. and Bawaska, M.S. (2009). Mithun: The pride animal of north-eastern hilly region of India. Vet. World. 2(12): 480-481.

Singh, J. and Patel, M.R. (1964). The osteology of skull of goat. J. Vet. Ani. Husb. Res. 8: 80-89.

Singh, P. (1984). Gross anatomical studies on the skull of camel (Camelus dromedarius). M.V.Sc. thesis submitted to the Haryana Agriculture University, Hisar, Haryana, India.

Smuts, M.W. and Bezuidenhout, A.J. (1987). Anatomy of the Dromedary. Clwerendon Press, Oxford, UK.

Sundaram, V., Dharani, P., Gnanadevi, R. and Kavya, R. (2019). Studies on clinical anatomy of the maxillofacial and mandibular regions of the Madras red sheep (Ovis aries) in India. Folia Morphol. 78(2): 389-393. 